\title{
Comparative analyses of leaf anatomy of dicotyledonous species in Tibetan and Inner Mongolian grasslands
}

\author{
MA JianJing ${ }^{1,3}$, JI ChengJun $^{1 *}$, HAN Mei ${ }^{1}$, ZHANG TingFang ${ }^{2}$, YAN XueDong ${ }^{2}$, HU Dong ${ }^{2}$, \\ ZENG Hui ${ }^{1,3}$ \& HE JinSheng ${ }^{1,4}$ \\ ${ }^{1}$ Department of Ecology, and Key Laboratory for Earth Surface Processes of Ministry of Education, Peking University, Beijing 100871, China; \\ ${ }^{2}$ College of Life Sciences, Capital Normal University, Beijing 100037, China; \\ ${ }^{3}$ Shenzhen Key Laboratory of Circular Economy, Shenzhen Graduate School, Peking University, Shenzhen 518055, China; \\ ${ }^{4}$ Key Laboratory of Adaptation and Evolution of Plateau Biota, Northwest Institute of Plateau Biology, Chinese Academy of Sciences, Xining \\ 810008, China
}

Received May 10, 2011; accepted October 13, 2011

\begin{abstract}
Knowledge of the leaf anatomy of grassland plants is crucial for understanding how these plants adapt to the environment. Tibetan alpine grasslands and Inner Mongolian temperate grasslands are two major grassland types in northern China. Tibetan alpine grasslands occur in high-altitude regions where the low temperatures limit plant growth. Inner Mongolian temperate grasslands are found in arid regions where moisture is the limiting factor. Few comparative studies concerning the leaf anatomy of grassland plants of the Tibetan Plateau and Inner Mongolian Plateau have been conducted. We examined leaf characteristics at 71 sites and among 65 species, across the alpine grasslands of the Tibetan Plateau and the temperate grasslands of the Inner Mongolian Plateau. We compared the leaf structures of plants with different life forms and taxonomies, and their adaptation to arid or cold environments. We explored relationships among leaf features and the effects of climatic factors (i.e., growing season temperature and precipitation) on leaf characteristics. Our results showed that (i) there were significant differences in leaf anatomy between Tibetan alpine and Inner Mongolian temperate grasslands. Except for mesophyll cell density, the values obtained for thickness of leaf tissue, surface area and volume of mesophyll cells were larger on the Tibetan Plateau than on the Inner Mongolian Plateau. (ii) Within the same family or genus, leaf anatomy showed significant differences between two regions, and trends were consistent with those of whole species. (iii) Leaf anatomy of woody and herbaceous plants also showed significant differences between the regions. Except for mesophyll cell density, the values obtained for the thickness of leaf tissue, and the surface area and volume of mesophyll cells were larger in herbaceous than in woody plants. (iv) Leaf anatomical traits changed accordingly. Total leaf thickness, thicknesses of lower and upper epidermal cells, and surface area and volume of mesophyll cells were positively correlated, while mesophyll cell density was negatively associated with those traits. (v) Growing season temperature had stronger effects on leaf anatomy than growing season precipitation. Although the communities in Tibetan and Inner Mongolian grasslands were similar in appearance, leaf anatomy differed; this was probably due to the combined effects of evolutionary adaptation of plants to environment and environmental stress induced by climatic factors.
\end{abstract}

\section{Tibetan Plateau, Inner Mongolian Plateau, steppe, meadow, leaf anatomy, dicotyledons}

Citation: $\quad$ Ma J J, Ji C J, Han M, et al. Comparative analyses of leaf anatomy of dicotyledonous species in Tibetan and Inner Mongolian grasslands. Sci China Life Sci, 2012, 55: 68-79, doi: 10.1007/s11427-012-4268-0

Grassland plants are mainly distributed in arid or low temperature regions, and in these regions the growth of trees is

*Corresponding author (email: jicj@pku.edu.cn) restricted [1]. As the third largest grassland ecosystem in the world, China's grasslands comprise approximately $40 \%$ of China's land area, and are of diverse types, from the temperate grasslands of the Inner Mongolian Plateau, and the 
alpine grasslands of the Tibetan Plateau, to the mountain grasslands in the Xinjiang Autonomous Region [2]. The temperate grasslands of the Inner Mongolian Plateau are mainly in arid and semi-arid regions; the dry habitat has high growing season temperatures, and plant growth is predominantly determined by precipitation [3]. The climate of the alpine grasslands of the Tibetan Plateau is mainly affected by the northwest monsoon; the humid habitat has lower growing season temperatures, and plant growth is limited by the low temperatures [4,5]. Our question was whether leaf anatomy in the alpine grasslands of the Tibetan Plateau was different from that in the temperate grasslands of the Inner Mongolian Plateau.

The effects of environmental factors such as low temperature, drought, light, and elevation, on leaf structures and the responses of leaf structures to the environment have been recognized for a long time, and ecological trends have been generalized [6-9]. Smaller leaf area, thicker epidermal thickness, thicker mesophyll tissue, and thicker leaves, for example, characterize plants in low temperature zones [9]. Increased number of palisade layers with small cell volume, decreased number of spongy layers with small cell volume, and smaller intercellular spaces characterize plants in zones of water shortage [10]. Smaller and thicker leaves, well-developed epidermal cuticles and trichomes, a thicker epidermal layer composed of small cells, the appearance of a hypodermal layer, well-developed palisade tissue, and tightly arranged spongy tissue characterize plants in zones of high light intensity [11-13]. Previous studies are characterized by insufficient sampling locations and few examined species $[14,15]$. Since plant anatomy is largely genetically determined, and leaf structural features change with environment, insufficient sampling locations or ecological data may not accurately reflect intrinsic relationships between anatomy and ecology [16,17]. On the Tibetan Plateau, in particular, where plants grow in regions of physiological drought and great diurnal temperature variation, leaf structural features remain unclear and infrequently reported.

The dynamics of leaf anatomy are determined by interactions among genotype, ontogenetic position, and environmental factors [18]. Large-scale studies generally contain various species, the genotypes of these species differ, their sensitivities to ecological factors may also vary, and plants with different taxonomies or from different functional groups may have different responses to environmental change; leading to the differences overwhelming the intrinsic relationships between leaf anatomy and environment $[19,20]$. It is therefore necessary to compare the responses of plants with different taxonomies and life forms.

Using paraffin microtomy and microscopic measurements, we investigated the leaf anatomy of 65 dicotyledonous species across 71 sampling sites on the Inner Mongolian Plateau and the Tibetan Plateau. We compared structural differences in the leaves of plants with different taxonomies and life forms; analyzing the relationships be- tween leaf anatomy and environmental factors (i.e., growing season temperature, and growing season precipitation). The leaves of dicotyledonous and monocotyledonous species show notable differences. Monocots are characterized by isobilateral leaves, enclosed terminal collateral veins, are without free terminal ends, and guard cells are arranged in lines. Dicots are characterized by bifacial leaves, opened terminal collateral veins, have free terminal ends, and scattered guard cells [21]. Variations in leaf structure inevitably lead to changed responses to environmental factors [22]. Analyzing the responses of dicot and monocot leaves to environmental factors is thus necessary. We will discuss the structural characteristics of monocotyledonous species in a later paper.

\section{Materials and methods}

\subsection{Study sites}

The study area included temperate grasslands on the Inner Mongolian Plateau (107.26-120.06 $\left.{ }^{\circ} \mathrm{E}, 38.41-49.51^{\circ} \mathrm{N}\right)$, and alpine grasslands on the Tibetan Plateau $\left(80.25-102.89^{\circ} \mathrm{E}\right.$, $\left.28.19-35.44^{\circ} \mathrm{N}\right)$. Our sampling areas covered five provinces and autonomous regions: Inner Mongolia, Ningxia, Gansu, Qinghai, and Tibet. The climate of the Inner Mongolian Plateau is a typical temperate continental monsoon: winters are long and cold, summers are warm and dry. The temperature decreases from southwest to northeast, and precipitation increases from southwest to northeast [23]. The elevation of the sampling sites ranges from 588 to $1458 \mathrm{~m}$, the mean growing season temperature (MAT) ranges from 14.8 to $20.4^{\circ} \mathrm{C}$, and growing season precipitation (MAP) from 146 to $316 \mathrm{~mm}$. The Tibetan Plateau is one of the largest alpine grasslands in the world with an average elevation of over $4000 \mathrm{~m}$. The solar radiation ranges from 0.586 to 0.795 $\mathrm{MJ} \mathrm{cm} \mathrm{cm}^{-2} \mathrm{a}^{-1}$, topographic variance is complex and ground temperature exhibits large regional differences, temperatures are low and show seasonal variation. Precipitation here is mainly affected by the southwest monsoon, and decreases gradually from southeast to northwest; the seasonal distribution of precipitation is extremely uneven. Rainy and dry seasons are sharply contrasting [24]. The elevation of the study sites on the Tibetan Plateau ranges from 2996 to $5249 \mathrm{~m}$, mean growing season temperature ranges from -1.0 to $13.5^{\circ} \mathrm{C}$, and precipitation from 85 to $383 \mathrm{~mm}$ (Table 1).

\subsection{Field sampling}

We conducted four consecutive sampling campaigns during the summers (July and August) of 2002-2005 and sampled 71 sites across the plateaus (Figure 1). Field sampling was conducted along the major roads of these plateaus. Nevertheless, sampling sites covered all the major grassland types in these areas. At each site $(10 \mathrm{~m} \times 10 \mathrm{~m})$, five plots $(1 \mathrm{~m} \times 1$ 
Table 1 Sampling site details

\begin{tabular}{ccc}
\hline & Tibetan Plateau & Inner Mongolian Plateau \\
\hline Plot number & 49 & 22 \\
Species number & 48 & 28 \\
Elevation $(\mathrm{m})$ & $4239(2996-5249)$ & $332(202-427)$ \\
Mean annual precipitation $(\mathrm{mm})$ & $382(110-624)$ & $251(146-316)$ \\
Growing season precipitation $(\mathrm{mm})$ & $263(85-383)$ & $2.2(-2.5-7.9)$ \\
Mean annual temperature $\left({ }^{\circ} \mathrm{C}\right)$ & $-1.3(-9.7-6.8)$ & $17.0(14.8-20.4)$ \\
Growing season temperature $\left({ }^{\circ} \mathrm{C}\right)$ & $7.3(-1.0-13.5)$ & $20.1(18.4-22.9)$ \\
Mean temperature for the warmest month $\left({ }^{\circ} \mathrm{C}\right)$ & $9.5(1.4-14.6)$ & $-18.0(-25.9$ to -9.2$)$ \\
Mean temperature for the coldest month $\left({ }^{\circ} \mathrm{C}\right)$ & $-13.1(-21.6$ to -2.5$)$ & \\
\hline
\end{tabular}

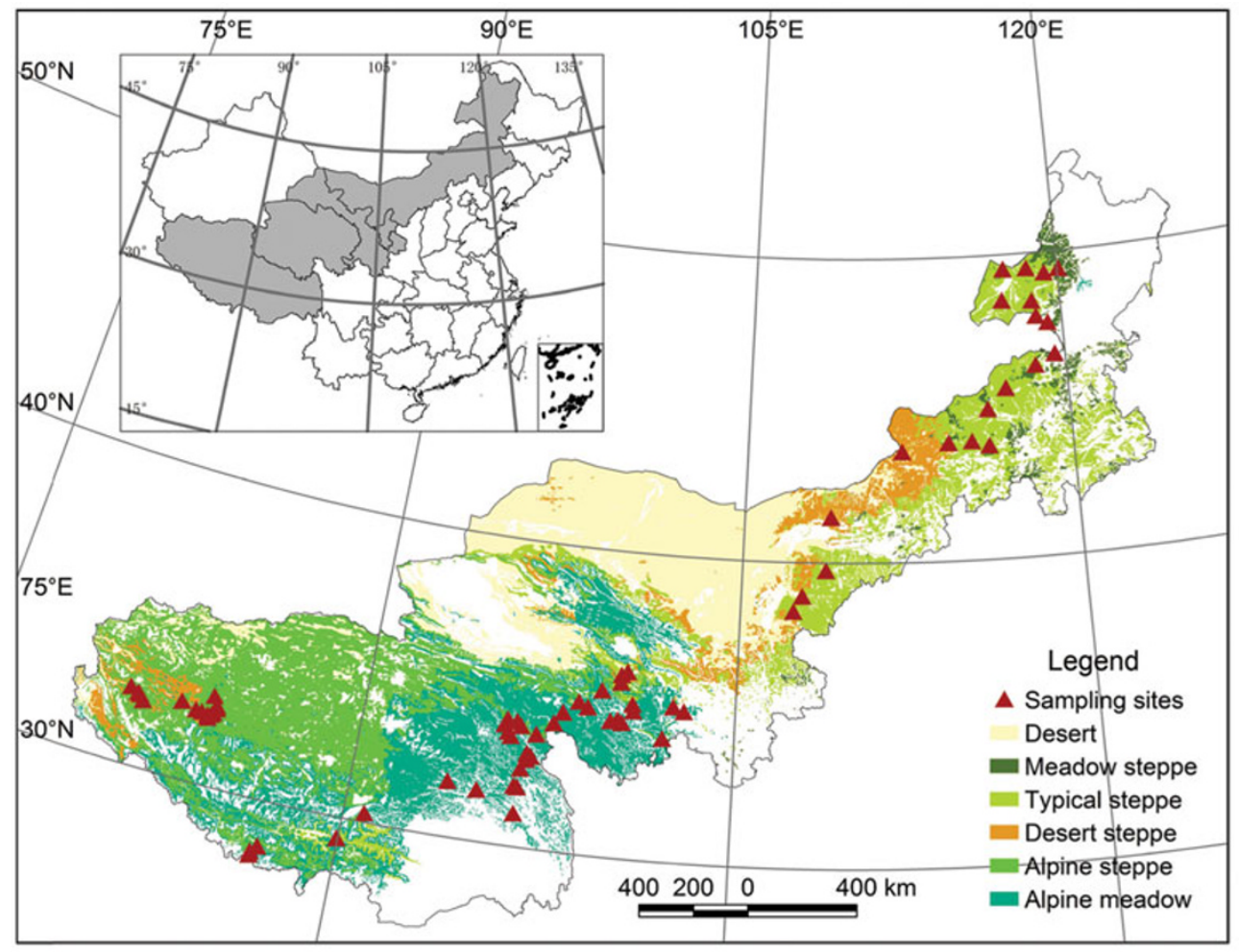

Figure 1 Location of sites sampled across alpine grasslands on the Tibetan Plateau and Inner Mongolian Plateau.

$\mathrm{m}, 4$ in the corners and 1 in the center) were set up. Altitude, latitude, and longitude of each site were recorded, and dominant or well-distributed species were selected and sampled. At each site, 3-5 individuals were sampled for each species, and healthy mature leaves of similar age and similar position were collected and fixed with FAA (formalin, acetic acid, alcohol). Nearly all collections were made at flowering time.

\subsection{Laboratory measurements}

From each leaf, three $0.5 \mathrm{~cm} \times 0.5 \mathrm{~cm}$ pieces were cut with a knife at $1 / 3$ of the distance from the leaf tip. Leaflets of compound leaves were considered to be functionally equivalent to simple leaves and were treated as such. Leaves were then dehydrated in a graded series of ethanol, embedded in paraffin, sectioned using a Leitz 2135 microtome, and stained with Safrania and Alcian green. All slides were mounted in Canada balsam after dehydration. Upper and lower epidermal thickness, mesophyll tissue thickness, density of mesophyll cells, length and width of mesophyll cells, and total leaf thickness were then measured using a Motic B5 microscope equipped with a microscopic imaging system (Figure 2). The surface area of mesophyll cells was calculated based on the following equations:

$$
\begin{gathered}
\mathrm{CSA}=\pi \cdot \mathrm{CW} \cdot(2 \mathrm{CL}+\mathrm{CW}) / 2, \\
\mathrm{CV}=\pi \cdot(\mathrm{CW} / 2)^{2} \cdot \mathrm{CL}(0.38+0.117 \mathrm{CL} / \mathrm{CW}),
\end{gathered}
$$

where CAS is the surface area of a mesophyll cell, $\mathrm{CW}$ is the mesophyll cell width, CL is the mesophyll cell length, and $\mathrm{CV}$ is the mesophyll cell volume. All measurements were made near the middles of leaves, avoiding midribs and margins, and five randomly chosen portions of leaf were 

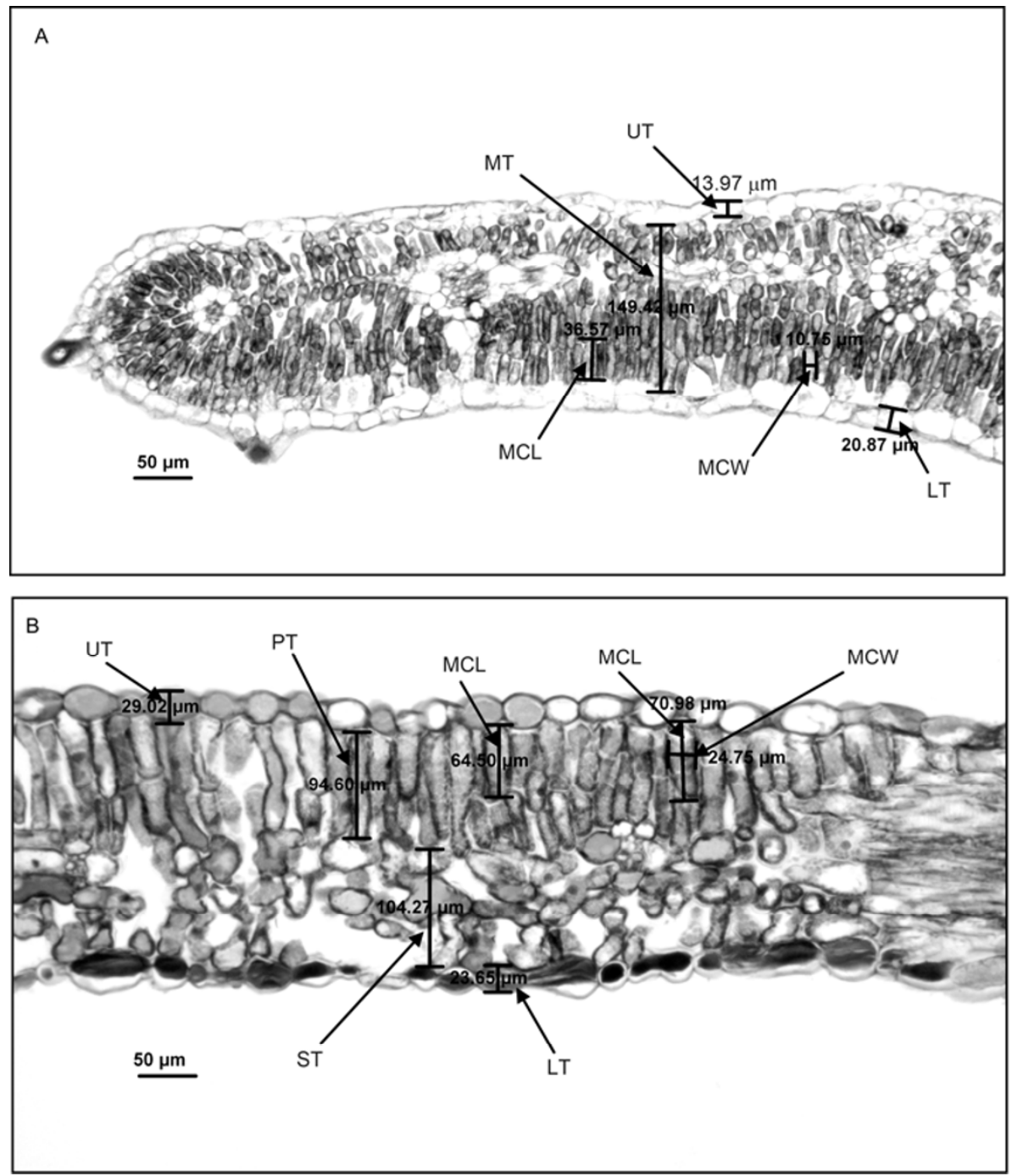

Figure 2 Cross-section of dicotyledonous leaves, showing the measured structural traits. A, Caragana microphylla. B. Rheum acetosa. UT, upper epidermal thickness; MT, mesophyll tissue thickness; MCL; mesophyll cell length; MCW, mesophyll cell width; LT, lower epidermal thickness; PT, palisade tissue thickness; ST, spongy tissue thickness.

measured for each slide.

\subsection{Climatic dataset}

The climate data were 30 year averages for temperature and precipitation (1970-1999) at 680 well-distributed climate stations across China, obtained from the world climate data information website (http://www.worldclim.org). Based on the latitude and longitude of each sampling site, the monthly mean temperature and precipitation were calculated through Kriging interpolation [25]. Based on our previous studies $[26,27]$, we used two climatic indices that have the highest explanatory power for ecological traits (i.e., growing season temperature and growing season precipitation).

\subsection{Statistical analyses}

All statistical analyses were performed using SPSS 16.0 software (SPSS, Inc., Chicago, IL, USA). One-way ANOVA analyses were conducted to compare leaf anatomical differences among different regions, life forms, and taxonomies. Pearson correlation analyses were used to examine correlations among leaf anatomical characteristics, and linear regression analysis was then performed to evaluate effects of climatic variables. We further examined leaf characteristics using principal component analysis (PCA). The first axis in PCA (explaining $68 \%$ of the variation) and environmental factors were analyzed with the purpose of understanding the climatic variables important in the first axis.

\section{Results}

\subsection{Dicotyledonous plants and leaf anatomy overview}

We sampled 65 species of plants in 20 families. Five families contained the most species: Fabaceae (26.2\%), Aster- 
aceae $(13.8 \%)$, Rosaceae (13.8\%), Salicaceae (7.7\%), and Polygonaceae $(7.7 \%$ ) (Table 2). In both the Tibetan alpine grasslands and the Inner Mongolian temperate grasslands, family Fabaceae had the most species (10 and 12, respectively). In the Asteraceae, Rosaceae, and Salicaceae there were more species in the Tibetan alpine grasslands $(9,7,4$, respectively) than in the Inner Mongolian temperate grasslands $(1,4,1)$.

The average values of leaf anatomical characters varied substantially between different species. Total leaf thickness, for example, varied from $88.4 \mu \mathrm{m}$ in Potentilla anserina to $617.6 \mu \mathrm{m}$ in Gentiana straminea, and mesophyll cell density from $9.3 \times 10^{-4} \mu^{-2}$ in Oxytropis sericopetala to $7.4 \times 10^{-3}$ $\mu^{-2}$ in Caragana jubata. Caragana stenophylla had the largest mesophyll cell surface area $\left(4247 \mu \mathrm{m}^{2}\right)$ and cell volume $\left(13431 \mathrm{\mu m}^{3}\right)$, while Potentilla fruticosa had the smallest $\left(460 \mu \mathrm{m}^{2}\right.$ and $\left.481 \mu \mathrm{m}^{3}\right)$.

\subsection{Leaf anatomy variances in two types of grasslands}

Leaf characteristics exhibited significant differences between the two regions. One-way ANOVA analyses showed that habitat had significant influence on leaf anatomy. In general, except for mesophyll cell density, the values of other leaf characteristics including total leaf thickness and leaf tissue thickness, mesophyll cell surface area and volume were larger in Tibetan alpine grasslands than in Inner Mongolian temperate grasslands. Among these leaf anatomical indexes, mesophyll cell volume was the most variable; the value in Tibetan alpine grasslands $\left(4.09 \times 10^{3} \mu \mathrm{m}^{3}\right)$ was about two times larger than the value in Inner Mongolian temperate grasslands $\left(2.04 \times 10^{3} \mu \mathrm{m}^{3}\right)$.
We chose four genera, Oxytropis, Potentilla, Caragana, and Salix, as representative genera for comparison of leaf structural differences in the two regions. These four genera were common with high percentages of species in our plots. Oxytropis, Potentilla, and Salix more often occurred in Tibetan Plateau plots (with frequencies of 71, 43, and 18), than in Inner Mongolian plots (3, 8, and 3). The times of Caragana species appeared in Tibetan Plateau plots and Inner Mongolian plots were 10 and 35 (data not shown).

In Oxytropis, upper and lower epidermal thickness, mesophyll tissue thickness, and total leaf thickness exhibited no significant differences between two plateau plants, while mesophyll cell density was larger on the Inner Mongolian Plateau than on the Tibetan Plateau. In Potentilla and Caragana, mesophyll cell density was larger in Inner Mongolia; however, the other leaf characteristics were larger in Tibet. In Salix, upper and lower epidermal thickness exhibited no significant differences; however, the other leaf characteristics showed similar patterns to Potentilla and Caragana (Figure 4). In summary, mesophyll cell density in four genera followed consistent patterns, i.e., larger values were obtained in Inner Mongolia than in Tibet. With the exception of Oxytropis, leaf component thickness in Tibet was greater than in Inner Mongolia in the three other genera. This means that within the same family or genus, leaf anatomy showed significant differences between the two regions, and trends were similar to those of whole species (Figure 3).

Comparative analyses of leaf anatomy among different life forms are shown in Figure 5. Leaf characteristics of the two regions also showed significant differences between woody and herbaceous plants $(P<0.01)$. Leaf tissue thick-

Table 2 Statistical analysis of grassland plants on the Tibetan Plateau and the Inner Mongolian Plateau

\begin{tabular}{|c|c|c|c|c|}
\hline Family & Species & Percentage of total species (\%) & Tibetan Plateau & Inner Mongolian Plateau \\
\hline Fabaceae & 17 & 26.2 & 12 & 10 \\
\hline Asteraceae & 9 & 13.8 & 1 & 9 \\
\hline Rosaceae & 9 & 13.8 & 4 & 7 \\
\hline Salicaceae & 5 & 7.7 & 4 & 2 \\
\hline Polygonaceae & 5 & 7.7 & 1 & 4 \\
\hline Lamiaceae & 2 & 3.1 & 0 & 2 \\
\hline Ranunculaceae & 2 & 3.1 & 0 & 2 \\
\hline Saxifragaceae & 2 & 3.1 & 1 & 1 \\
\hline Apiaceae & 1 & 1.5 & 1 & 1 \\
\hline Euphorbiaceae & 1 & 1.5 & 0 & 1 \\
\hline Brassicaceae & 1 & 1.5 & 0 & 1 \\
\hline Primulaceae & 1 & 1.5 & 0 & 1 \\
\hline Asclepiadcaeae & 1 & 1.5 & 1 & 1 \\
\hline Tamaricaceae & 1 & 1.5 & 0 & 1 \\
\hline Elaeagnaceae & 1 & 1.5 & 0 & 1 \\
\hline Betulaceae & 1 & 1.5 & 1 & 0 \\
\hline Chenopodiaceae & 1 & 1.5 & 0 & 1 \\
\hline Ulmaceae & 1 & 1.5 & 1 & 0 \\
\hline
\end{tabular}



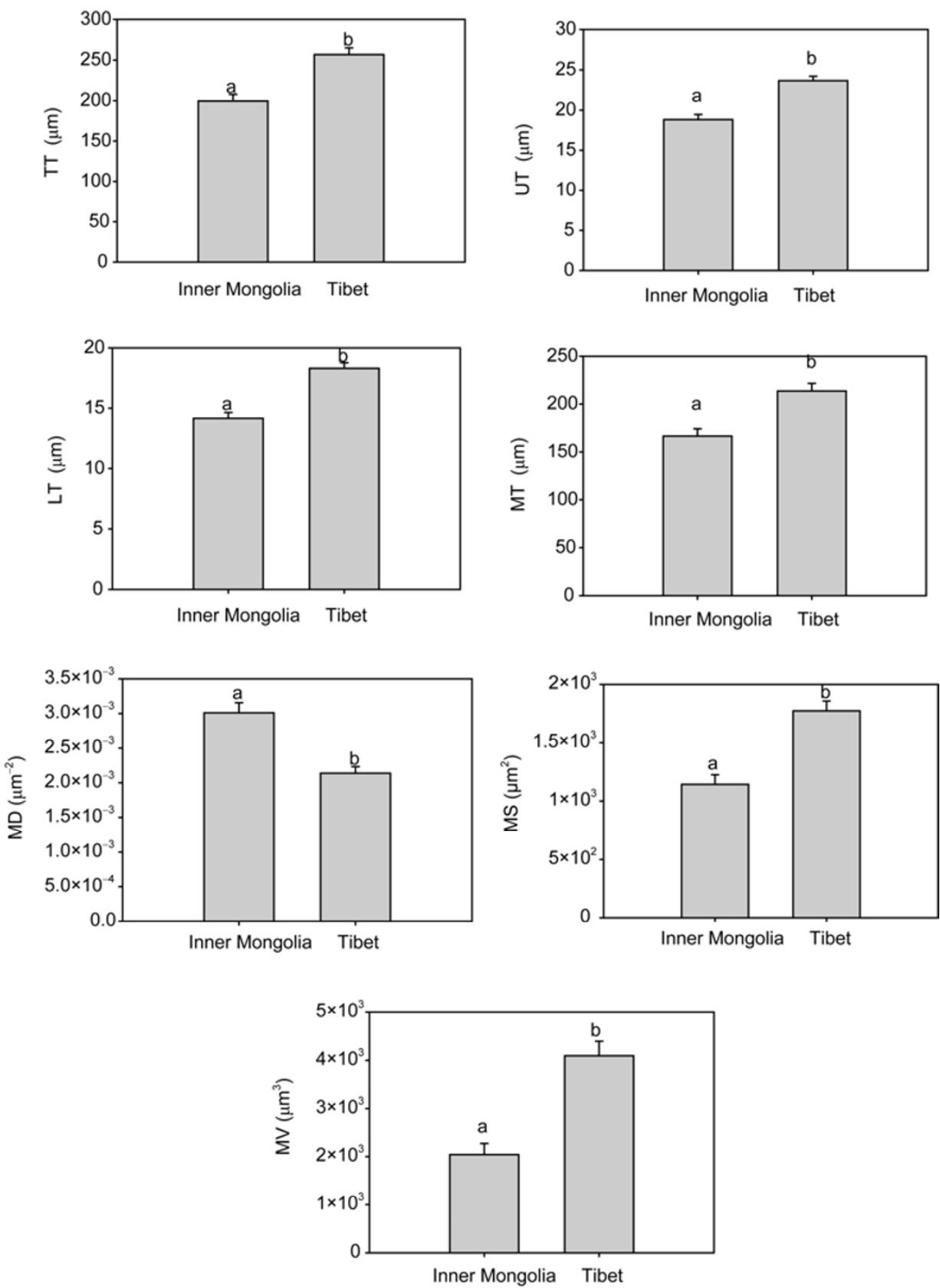

Figure 3 Histogram of mean values of leaf anatomy traits on the Tibetan Plateau and Inner Mongolian Plateau.

ness of herbaceous plants $(250 \mu \mathrm{m})$ was greater than of woody plants $(200 \mu \mathrm{m})$. The surface area and volume of mesophyll cells was $1700 \mu \mathrm{m}^{2}$ and $4000 \mu \mathrm{m}^{3}$ for herbaceous plants; larger than those for woody plants $\left(1300 \mu \mathrm{m}^{2}\right.$ and $2700 \mu^{3}$ ); only for mesophyll cell density, the former was smaller than the latter.

\subsection{Leaf anatomy traits change in coordination with each other}

The relationships between leaf characteristics in the two regions are shown in Table 3 . Each pair of leaf anatomy traits was significantly correlated. Mesophyll cell density showed significant negative correlations with the other anatomic indexes $(P<0.001)$, while there was a positive correlation among other indexes, indicating that leaf anatomical characteristics were cooperatively related. Total leaf thickness and leaf tissue thickness, as well as mesophyll cell surface area and volume, had the strongest correlations, with correlation coefficients of 0.987 and 0.989 , respectively. Thus, although the increases in upper and lower epidermal thickness, the increases in mesophyll tissue thickness and mesophyll cell volume, and the decrease in mesophyll cell density all dominantly contributed to the increase 

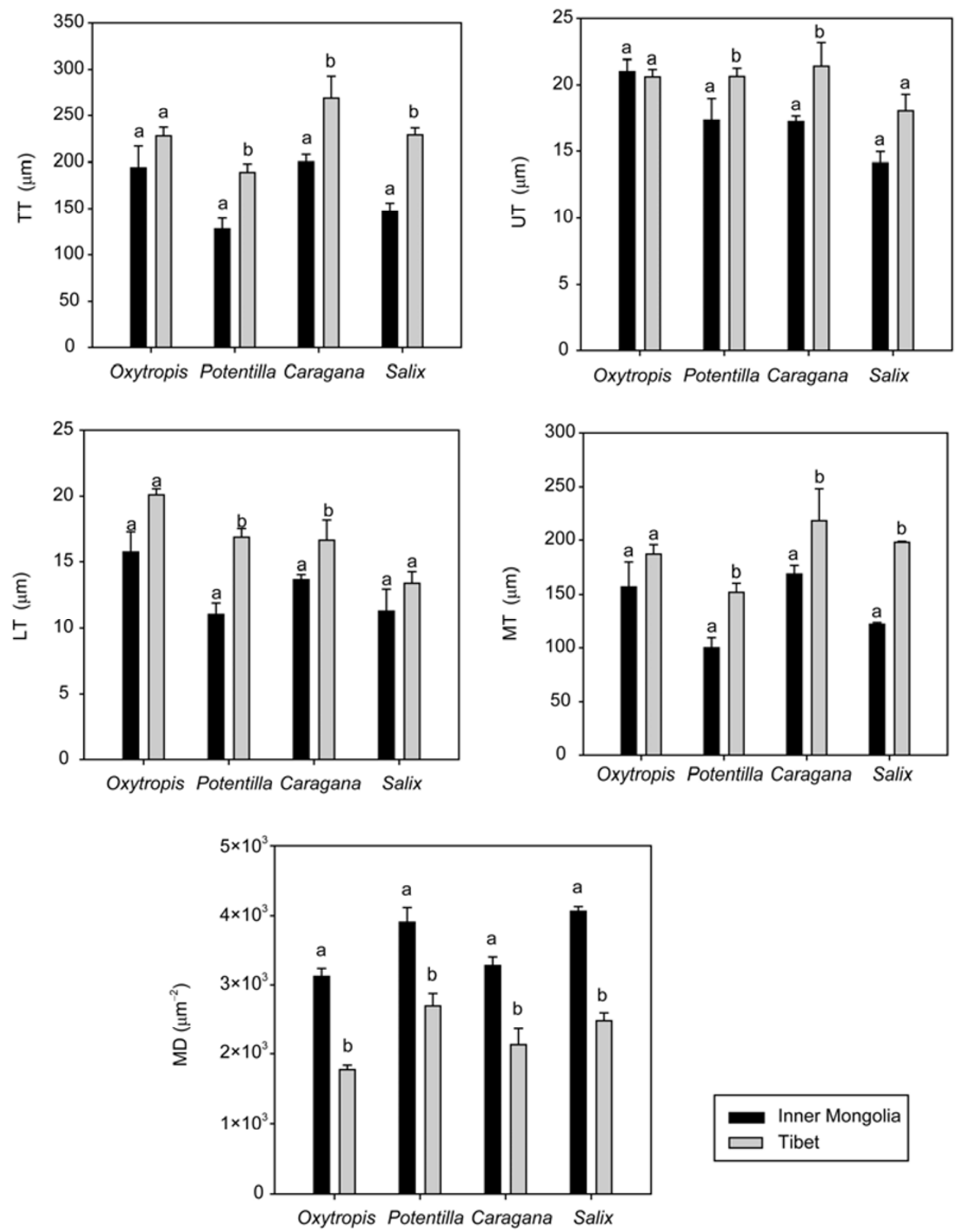

Figure 4 Histogram of mean values of leaf anatomy traits in species within four genera on the Tibetan Plateau and Inner Mongolian Plateau.

in total leaf thickness, mesophyll tissue thickness was the largest contributor.

\subsection{Leaf characteristics show weak relationship with temperature}

Pearson correlation analyses were used to assess the relationships among leaf characteristics, and we found that these traits were significantly correlated. PCA analyses were therefore used to simplify the index. Analyzing the explanation rate of the principal component revealed: the $\lambda$ value of the first axis was 4.76 with an explanation rate of $68.0 \%$, while the $\lambda$ value of the second axis was 0.89 and therefore lower than 1 . Analysis of the principal component matrix of leaf characteristics showed that the absolute value of PCA1 was approximately close to 1 (Table 4), indicating that PCA1 is able to reflect a coordinated change in leaf anatomy.

Regression analysis of the first PCA axis and environmental factors is shown in Table 5. At species level the first axis had a weak negative correlation with growing season temperature $\left(R^{2}=0.13, P<0.001\right)$, but no significant relationship with growing season precipitation. At genus level, Caragana exhibited similar trends $\left(R^{2}=0.36, P<0.05\right)$. The first axis for Oxytropis and Potentilla had no significant relationship with growing season precipitation or growing season temperature, while the first axis in Salix showed significant negative correlation with growing season tempera- 

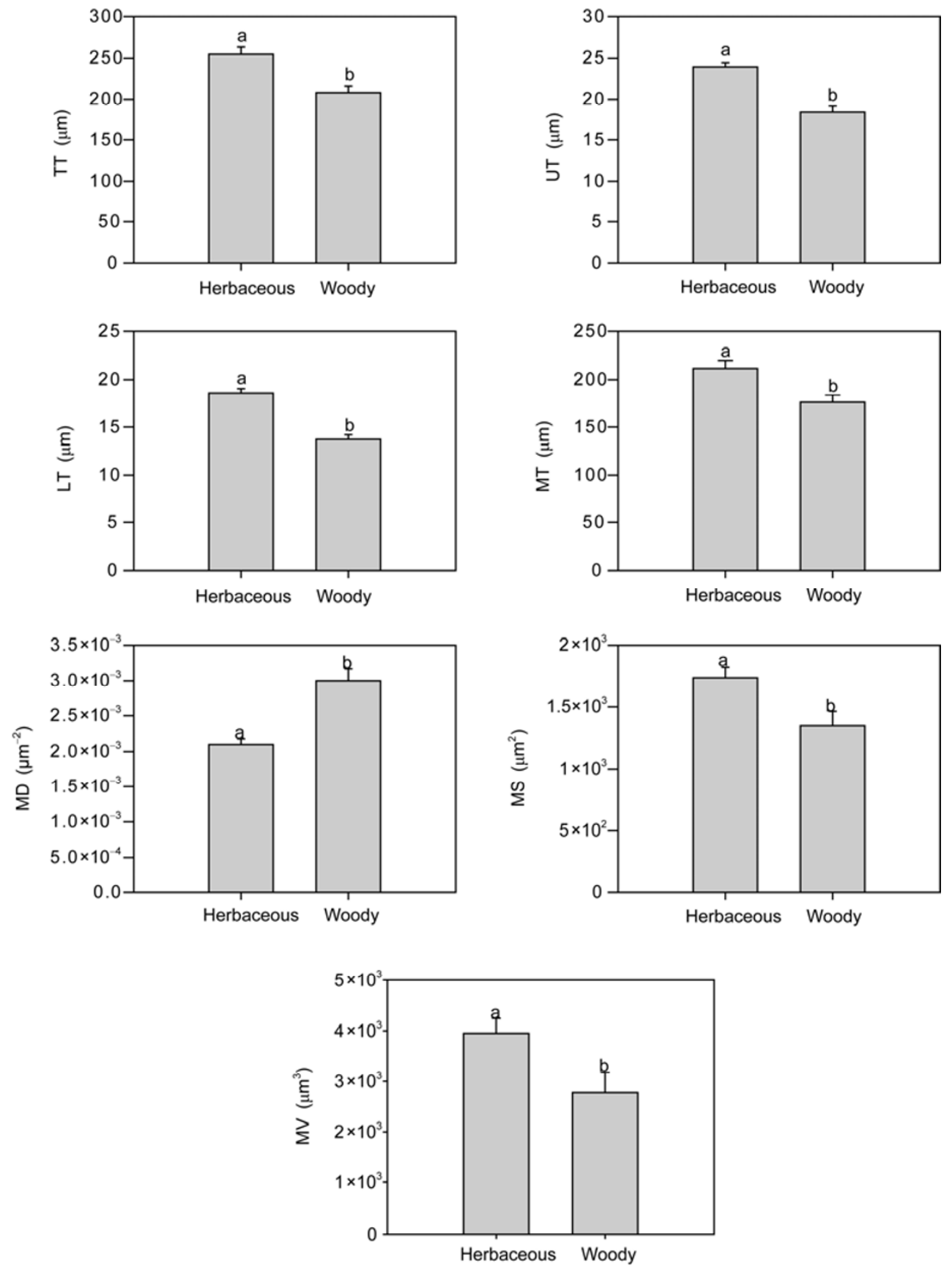

Figure 5 Histogram of mean values of leaf anatomy traits in species with different life forms on the Tibetan Plateau and Inner Mongolian Plateau.

Table 3 Relationships between leaf anatomy traits of dicotyledonous species ${ }^{\mathrm{a})}$

\begin{tabular}{cccccccc}
\hline & UT $(\mu \mathrm{m})$ & MT $(\mu \mathrm{m})$ & LT $(\mu \mathrm{m})$ & TT $(\mu \mathrm{m})$ & MD $\left(\mu \mathrm{m}^{-2}\right)$ & MS $\left(\mu \mathrm{m}^{2}\right)$ & MV $\left(\mu \mathrm{m}^{3}\right)$ \\
\hline UT $(\mu \mathrm{m})$ & & $0.566^{* *}$ & $0.745^{* *}$ & $0.636^{* *}$ & $-0.463^{* *}$ & $0.596^{* *}$ & $0.596^{* *}$ \\
MT $(\mu \mathrm{m})$ & 148 & & $0.564^{* * *}$ & $0.987^{* * *}$ & $-0.606^{* *}$ & $0.664^{* *}$ & $0.644^{* * *}$ \\
LT $(\mu \mathrm{m})$ & 148 & 148 & & $0.625^{* * *}$ & $-0.507^{* *}$ & $0.406^{* *}$ & $0.386^{* *}$ \\
TT $(\mu \mathrm{m})$ & 148 & 148 & 148 & & $-0.644^{* *}$ & $0.692^{* *}$ & $0.672^{* * *}$ \\
MD $\left(\mu \mathrm{m}^{-2}\right)$ & 132 & 132 & 132 & 132 & & $-0.579^{* *}$ & $-0.533^{* *}$ \\
MS $\left(\mu \mathrm{m}^{2}\right)$ & 132 & 132 & 132 & 132 & 132 & $0.989^{* * *}$ \\
MV $\left(\mu \mathrm{m}^{3}\right)$ & 132 & 132 & 132 & 132 & 132 & 132 & \\
\hline
\end{tabular}

a) The upper-right part of the table shows the correlation index among leaf characteristics while the lower-left part of the table shows the number of corresponding samples. The shade of color means the value of correlation cofficient. **, $P<0.01 ; *, P<0.05$. UT, upper epidermal thickness; MT, mesophyll tissue thickness; LT, lower epidermal thickness; TT, total leaf thickness; MD, mesophyll cell density; MS, mesophyll cell surface area; MV, mesophyll cell volume. 
Table 4 PCA analyses of leaf anatomical traits. PCA1, first principal component; PCA1 explains $68.0 \%$ of the variation, PCA2 explains $12.7 \%$, and PCA3 explains $9.2 \%$

\begin{tabular}{cc}
\hline Leaf anatomical characteristics & PCA1 \\
\hline Total leaf thickness & 0.919 \\
Upper epidermal thickness & 0.780 \\
Lower epidermal thickness & 0.720 \\
Mesophyll tissue thickness & 0.879 \\
Mesophyll cell density & -0.745 \\
Mesophyll cell surface area & 0.863 \\
Mesophyll cell volume & 0.845 \\
\hline
\end{tabular}

ture $\left(R^{2}=0.54, P<0.01\right)$, and significant positive correlation with growing season temperature $\left(R^{2}=0.31, P<0.05\right)$.

\section{Discussion}

\subsection{Similarities and differences in leaf anatomy in grassland plants on the Tibetan Plateau and the Inner Mongolian Plateau}

Plants and their growth environments are a unified whole, and the long-term effects of environment on plants can alter leaf morphology, physiological function, and ecology [28]. On the other hand, environments have a filter effect on the species banks in certain regions: Only those able to adapt to the environment can survive, and those that do not will gradually become extinct there. Although the results of these two processes are similar, they show obvious differences in mechanism. The temperate grasslands on the Inner Mongolian Plateau are in arid regions where plant growth is regulated by water deficits [3]. Previous studies have shown that compared with mesophytic plants, xerophilous plants have thicker leaves, smaller mesophyll cells, and well developed palisade tissue [29]. In Tibetan alpine grasslands, lower temperatures and the larger range in temperature induced by the high elevation can affect the efficiency of water absorption. Plants therefore show characteristic xerophilous leaves: smaller, thicker, and with more mesophyll cells $[28,30-33]$. In addition, the number of layers of palisade tissue increases and the thickness of lower and upper epidermal cells becomes larger in high-altitude regions [34,35]. Since in both regions, the environment can cause physiological drought, leaf traits in the two regions display some common features: thicker epidermis and total leaf thickness, and well-developed palisade tissue. On the Inner Mongolian
Plateau, such structural features can reduce water transpiration, improve photosynthetic efficiency, and avoid injury of the mesophyll cells by strong light [36]. In the Tibetan alpine grasslands, both growing season precipitation and annual mean precipitation are higher than on the Inner Mongolian Plateau (Table 1); structural features may not be induced by precipitation, but by the combination of low oxygen, low temperature, and strong radiation [35]. Our results indicate that structural features under different conditions may have adaptive significance.

The one-way ANOVA showed that the values of leaf anatomical traits including total leaf thickness and leaf tissue thickness, surface area and volume of mesophyll cells were larger in Tibetan alpine grasslands than the corresponding values in Inner Mongolian temperate grasslands. Abrams et al. stated that blades thicken as degree of drought increases [37]. However, Körner argued that drought does not play a decisive role in determining leaf thickness in alpine plants [38]. Strong ultraviolet radiation at high altitudes can affect leaf development, and thicker leaves can prevent injury by strong radiation $[11,39]$. Generally, the Tibetan Plateau has low temperatures and a wider temperature range; a thicker blade and epidermis can lessen the temperature range between the internal and external spaces of a blade, and keep blade temperature stable [40].

Values for mesophyll cell volume and surface area were smaller in Inner Mongolian grassland plants than in Tibetan grassland plants, while mesophyll cell density showed a contrasting result; indicating that mesophyll cells in Inner Mongolian plants are smaller and more tightly arranged. Zhang et al. [8] stated that smaller and more tightly arranged mesophyll cells confer stronger drought resistance on white elms. Since plant growth is mainly determined by precipitation in Inner Mongolian grasslands [27], such mesophyll cell characters should have strong drought resistance.

The growing season temperature in Tibetan grasslands is lower than in Inner Mongolian grasslands. Previous studies have shown that low temperatures can affect the meristematic cells of young leaves when they are still within buds, and cause them to develop into larger leaves [6]. Greater cold means a longer winter and later plant budding. Leaf growth coincides with the month of greater water and higher temperatures: favorable for cell development, and also likely to result in larger cells [6]. Low temperatures in Ti-

Table 5 Relationships between PCA1 for leaf anatomy and the linear regression parameters for growing season temperature and growing season precipitation $^{\mathrm{a})}$

\begin{tabular}{|c|c|c|c|c|c|c|}
\hline & \multicolumn{3}{|c|}{ Growing season temperature $\left({ }^{\circ} \mathrm{C}\right)$} & \multicolumn{3}{|c|}{ Growing season precipitation (mm) } \\
\hline & $a_{0}$ & $t$ & $R^{2}$ & $a_{0}$ & $t$ & $R^{2}$ \\
\hline Whole species & 4.00 & -4.416 & $0.130^{* * *}$ & 0.225 & -0.238 & 0.000 \\
\hline Oxytropis & -1.637 & 0.209 & 0.052 & -0.659 & 0.005 & 0.023 \\
\hline Potentilla & 0.087 & -0.080 & 0.255 & -0.070 & -0.003 & 0.095 \\
\hline Caragana & 1.295 & -0.131 & $0.360^{*}$ & -1.865 & 0.004 & 0.161 \\
\hline Salix & 0.558 & -0.096 & $0.537^{* *}$ & -3.257 & 0.009 & $0.311^{*}$ \\
\hline
\end{tabular}

a) *, $P<0.05 ; * *, P<0.01 ; * * *, P<0.001 . a_{0}$, constant; $t$, slope. 
betan grasslands may therefore play a key role in explaining the larger volume of these mesophyll cells.

Plants on the Tibetan Plateau are grown at high altitudes; the air is thin and the well-developed ventilation tissue can make up for the deficit of $\mathrm{CO}_{2}$ in the atmosphere, thus improving photosynthetic efficiency, and benefiting growth and development [35]. Körner stated that in the mature leaves of alpine plants, intercellular spaces generally accounted for $25 \%-35 \%$ of total leaf volume [38]. This may partly explain why the leaves of plants in Tibetan grasslands have smaller mesophyll cell density.

Our comparison of leaf anatomy in four genera between the Tibetan alpine grasslands and Inner Mongolian temperate grasslands showed that except for Oxytropis, the genera studied all showed similar trends to those of whole species (Figure 3), i.e., except for mesophyll cell density, the values of the other leaf characteristics including total leaf thickness and leaf tissue thickness, surface area and volume of mesophyll cells were larger in Tibetan alpine grasslands than in Inner Mongolian temperate grasslands. This confirms the former conclusion based on generic and family level analyses. Comparison of total leaf thickness among the four genera indicates that Caragana has the thickest leaves, and that its leaf thickness and strong water-holding capacity should be important adaptations to the adverse environment. Thus Caragana species are able to be well distributed in steppe and desert regions, as they are resistant to drought, cold, and barren environments [41].

Life form is a result of the long term adaptation of plants to environment [42]. Leaves of plants with different life forms usually have different structures, and different nutritional and drought resistance mechanisms [43-47]. Liu [47] analyzed the leaf osmotic potential of plants grown in Hunshandake Sandland, China, and found that the leaves of shrubs had the lowest osmotic potential, leaves of trees had medium potential, and leaves of herbs had the highest osmotic potential. On the whole, herbaceous plants have thicker leaves than woody plants on the Tibetan and Inner Mongolian Plateaus. This can be interpreted as adaptive strategies based on life form. Herbaceous species generally have shallower root systems, water transport power is small, and water uptake ability is weak; only the thicker blade can efficiently reduce water transpiration, maintaining more water in the mesophyll cells, and therefore have greater osmotic potential. In contrast, woody species generally have relatively deep root systems, water transport power is large, and absorbent ability is strong; maintaining more water from transpiration is not a critical, and they may develop many adaptations not limited to enhancement of leaf epidermal thickness.

\subsection{Leaf anatomy traits change in coordination with each other}

On both Tibetan and Inner Mongolian Plateaus, leaf traits of dicots are significantly correlated. Only mesophyll cell density shows negative correlation with the other anatomy traits; the others are significantly and positively correlated. Thicker leaves generally have larger mesophyll volume and lower mesophyll cell density. Because of this correlation, the leaf characters over different regions, different genera, and different life forms show consistent trends. At whole species level or at generic level, values of thicknesses of leaf components, and the volumes and surface areas of mesophyll cells are larger in Tibetan grasslands than in Inner Mongolian grasslands, while mesophyll cell density shows a contrasting result. Values of the thickness of leaf components and the volumes and surface areas of mesophyll cells are larger in herbaceous plants than in woody plants, and mesophyll cell density shows the opposite result.

This correlated change in leaf anatomy may be an evolutionary strategy. Plants may have not developed various combinations of structural traits in the process of evolution. A plant with a thicker blade but smaller mesophyll cells and larger mesophyll cell density, for example, seldom or never exists. Recently, researchers in the field of leaf functional traits put forward the concept of a leaf economics spectrum [48], i.e., as leaf longevity shortens, specific leaf area, leaf nitrogen levels, and photosynthetic rate tend to increase, and plants consequently invest less in leaf morphogenesis. As leaf longevity increases, specific leaf area, leaf nitrogen levels, and photosynthetic rate tend to decrease, and plants consequently invest more in leaf morphogenesis. Therefore, the leaf anatomical traits of Tibetan and Inner Mongolian Plateau plants exhibit coordinated changes, suggesting a kind of leaf economics spectrum.

\subsection{Leaf anatomical characteristics have weak negative correlation with temperature at whole species level}

PCA analyses indicated that the first axis (PAC 1) was able to explain the largest proportion of variation in leaf structure. PCA 1 of whole species and Caragana were negatively correlated with growing season temperature, and had no relationship with growing season precipitation. The first axis for Oxytropis and Potentilla had no significant relationship either with growing season precipitation or growing season temperature. The first axis for Salix showed significant negative correlation with growing season temperature, and significant positive correlation with growing season precipitation. Species of Oxytropis and Potentilla are mainly distributed in Tibetan grasslands, where the range in growing season temperature is small (less than $5^{\circ} \mathrm{C}$ ); this may be a reason why these species are not sensitive to temperature. Precipitation is not a primary limiting factor for alpine plants [38], so Oxytropis and Potentilla species do not show a notable relationship with precipitation. Species of Caragana and Salix are well distributed in both Tibetan and Inner Mongolian Plateaus, where the range in growing season temperature is large (more than $15^{\circ} \mathrm{C}$ ). The PCA 1 of 
species in these genera shows negative correlation with growing season temperature. Caragana is distributed on both Tibetan and Inner Mongolian Plateaus. The lower temperatures are a limiting factor for Tibetan grassland species, and moist conditions in the growing season can offset the effects of drought; as a result, Caragana species show no significant relationship with precipitation. Although species of Salix are distributed across both Tibetan and Inner Mongolian Plateaus, they are mainly found in Tibetan grasslands. The effects of lower temperatures and the moist climate are greater than the effects of drought; the PCA 1 of Salix species shows significant negative correlation with growing season temperature.

Species in different genera or families have different sensitivities to various ecological factors; this may result in leaf characteristics having no significant relationship with climatic factors $[19,20]$. However, on the whole, in our sampling plots in the Tibetan alpine grasslands and Inner Mongolian temperate grasslands, the PCA 1 of whole species had weak negative correlations with growing season temperature and no significant relationship with precipitation; indicating that the effects of temperature were more notable than those of precipitation across the study area.

\section{Conclusion}

We examined the leaf anatomy of dicotyledonous species across alpine grasslands on the Tibetan Plateau and temperate grasslands on the Inner Mongolian Plateau, by means of paraffin sectioning. Our results showed that (i) the leaf anatomy of plants in Tibetan grasslands was different from that of plants in the Inner Mongolian grasslands. Except for the density of mesophyll cells, the values of other traits for Tibetan Plateau plants, such as the thickness of leaf components and blade, and the surface area and volume of mesophyll cells are larger than those for Inner Mongolian Plateau plants. Compared with mesophytic plants, plants on the Inner Mongolian Plateau have thicker leaves, smaller and more tightly arranged mesophyll cells, and thus show the characteristics of drought resistance. (ii) Within the same family or genus, leaf characteristics showed significant differences between the two regions, and trends are similar to those of whole species. The values of leaf tissue thickness are larger in herbaceous plants than in woody plants; this is probably due to different adaptive mechanisms. (iii) Leaf anatomical traits in the two regions change in coordination with each other. Leaf characteristics of different regions, different families or genera, and different life forms all show similar trends. In general, the PCA1 of leaf anatomical traits in the two regions shows weak negative relationships with growing season temperature, and no significant associations with growing season precipitation; indicating that growing season temperature has greater effects on leaf anatomy than does growing season precipitation.

We thank the members of the Peking University Sampling Campaign Teams to the Tibetan Plateau and the Inner Mongolia Autonomous Region for their assistance in field investigations. We also thank Zuo WenYun, Zhou Meng, and Li XueFei for their assistance in laboratory analyses. This work was supported by the Funds for Creative Research Groups of the National Natural Science Foundation of China (Grant No. 31021001) and the Funds of the Chinese Academy of Sciences for Key Topics in Innovation Engineering (Grant No. KSCX2-YW-Z-0806).

1 Breckle S W. Walter's Vegetation of the Earth. 4th ed. New York: Springer-Verlag, 2002

2 Piao S L, Fang J Y, He J S, et al. Spatial distribution of grassland biomass in China. Acta Phytoecol Sin, 2004, 28: 491-498

3 Chen Z Z, Wang S P. China Typical Grassland Ecosystem. Beijing: Science Press, 2000

4 Ma W H, He J S, Yang Y H, et al. Environmental factors covary with plant diversity-productivity relationships among Chinese grassland sites. Global Ecol Biogeogr, 2010, 19: 233-243

5 Li W H, Zhou X M. Ecosystems of Qinghai-Xizang (Tibetan) Plateau and Approaches for Their Sustainable Management. Guangzhou: Guangdong Science and Technology Press, 1998

6 Fei S L, Fang J Y, Fan Y J, et al. Anatomical characteristics of leaves and woods of Fagus lucida and their relationship to ecological factors in Mountain Fanjingshan, Guizhou, China. J Integr Plant Biol, 1999, 41: 1002-1009

7 Zhang Y C, Zhang J N. Primary study on anatomical structure of leaves of Scorzonera mongolia Maxim. in saline environment. J Ningxia Agricult College, 2001, 22: 38-39

8 Zhang H X, Liu G H, Cui X P. Affection of aridity to anatomical structure of leave of Ulmus pumila L. var. sabulosa. Bull Bot Res, 2005, 25: 39-44

9 Rocas G, Scarano F R, Barros C F. Leaf anatomical variation in $\mathrm{Al}$ chornea triplinervia (Spreng) Mull. Arg. (Euphorbiaceae) under distinct light and soil water regimes. Bot J Linnean Soc, 2001, 136: 231-238

10 Chartzoulakis K, Patakas A, Kofidis G, et al. Water stress affects leaf anatomy, gas exchange, water relations and growth of two avocado cultivars. Sci Horticult, 2002, 95: 39-50

11 Mendes M M, Gazarini L C, Rodrigues M L. Acclimation of Myrtus communis to contrasting Mediterranean light environments-effects on structure and chemical composition of foliage and plant water relations. Environ Exp Bot, 2001, 45: 165-178

12 Cai Y L, Song Y C. Adaptive ecology of lianas in Tiantong evergreen broad-leaved forest, Zhejiang, China I. leaf anatomical characters. Acta Phytoecol Sin, 2001, 25: 90-98

13 Rocas G, Barros C F, Scarano F R. Leaf anatomy plasticity of Alchornea triplinervia (Euphorbiaceae) under distinct light regimes in a Brazilian montane Atlantic rain forest. Trees Struct Funct, 1997, 11: 469-473

14 Shi H Y, Wang Y F, Gao H Y. Adaptation of anatomical structures of the leaves of Saussurea stella Maxim to the alpine environment. Guihaia, 2010, 30: 621-625

15 Wang H Q, Xu Z, Qi J. Prospect and progress of leaf blade comparative anatomy of Poaceae in China. Grassland Turf, 2009, 133: 93-97

16 He D M, Liu Q, Lin B, et al. Adaptation of leaf anatomical characteristics of eleven understory species to different environments in Coniferous plantations. Acta Ecol Sin, 2008, 28: 4739-4749

17 Cui X P, Liu G H, Zhan R L. Comparison of leaf anatomical structure between Salix gordejevii growing under contrasting habitats of Otingdag Sandland and Salix microtachya var. bordensis growing on the lowlands of dunes. Acta Ecol Sinica, 2006, 26: 1842-1847

18 Lake J A, Quick W P, Beerling D J, et al. Plant development-signals from mature to new leaves. Nature, 2001, 411: 154-154

19 Pyankov V I, Kondratchuk A V, Shipley B. Leaf structure and spe- 
cific leaf mass: the alpine desert plants of the Eastern Pamirs, Tadjikistan. New Phytol, 1999, 143: 131-142

20 Rury P M, Dickison W C. Structural Correlations among Wood, Leaves and Plant Habit. New York: Academic Press, 1984

21 Xie C Z. Difference and relationship between monocotyledonous plants and dicotyledonous plants. Plants, 1983, 3: 24-25

$22 \mathrm{Li} \mathrm{F} \mathrm{L,} \mathrm{Bao} \mathrm{W} \mathrm{K.} \mathrm{Responses} \mathrm{of} \mathrm{the} \mathrm{morphological} \mathrm{and} \mathrm{anatomical}$ structure of the plant leaf to environmental change. Chin Bull Bot, 2005, 22: 118-127

23 The Integrated Investigation Team in Inner Mongolia and Ningxia, CAS. Vegetation of Inner Mongolia. Beijing: Science Press, 1985

24 Yang Y H, Piao S L. Variations in grassland vegetation cover in relation to climatic factors on the Tibetan Plateau. J Plant Ecol, 2006, 30: $1-8$

25 Hijmans R J, Cameron S E, Parra J L, et al. Very high resolution interpolated climate surfaces for global land areas. Int J Climatol, 2005, 25: $1965-1978$

26 He J S, Wang X P, Flynn D F B, et al. Taxonomic, phylogenetic and environmental trade-offs between leaf productivity and persistence. Ecology, 2009, 90: 2779-2791

27 He J S, Fang J Y, Wang Z H, et al. Stoichiometry and large-scale patterns of leaf carbon and nitrogen in the grassland biomes of China. Oecologia, 2006, 149: 115-122

28 Gao J P, Wang Y H, Chen D F. Anatomical characteristics of leaf epidermis and vessel elements of Schisandra sphenanthera from different districts and their relationships to environmental factors. Acta Bot Boreali-occident Sin, 2003, 23: 715-723

29 Li H Q, Ma W Y. The main indexes and analysis methods of drought resistant comparison on sand plants. Arid Zone Res, 1998, 15: 12-15

30 Kofidis G, Bosabalidis A M, Moustakas M. Contemporary seasonal and altitudinal variations of leaf structural features in Oregano (Origanum vulgare L.). Ann Bot, 2003, 92: 635-645

31 Li C Y, Zhang X J, Liu X L, et al. Leaf morphological and physiological responses of Quercus aquifolioides along an altitudinal gradient. Silva Fenn, 2006, 40: 5-13

32 Sam O, Jerez E, Dell'Amico J, et al. Water stress induced changes in anatomy of tomato leaf epidermes. Biol Plantar, 2000, 43: 275277

33 Bosabalidis A M, Kofidis G. Comparative effects of drought stress on leaf anatomy of two olive cultivars. Plant Sci, 2002, 163: 375-379

34 Li C, Cheng M, Tang Y D, et al. Characteristics comparison of leaf anatomy structure and photosynthesis of two Salix species at Qinghai-Xizang Plateau. Acta Bot Boreali-occident Sin, 2009, 29: 275-
282

35 Shi H Y, Wang Y F, Wang J H. Studies on the anatomical structures of leaves of seven Saussurea DC. species on the Qinghai-Tibetan Plateau with different altitude. Bulletin of Botanical Research, 2009, 29: 289-294

36 Dong J F, Li C H, Liu H G, et al. Analysis of drought resistance by leaf anatomical structure of six species of sandy willows. J Desert Res, 2009, 29: 480-484

37 Abrams M D, Kubiske M E, Mostoller S A. Relating wet and dry year ecophysiology to leaf structure in contrasting temperate tree species. Ecology, 1994, 75: 123-133

38 Körner C. Alpine Plant Life. Functional Plant Ecology of High Mountain Ecosystems. Berlin: Springer, 1999

39 Shi S B, Zhu W Y, Li H M, et al. Photosynthesis of Saussurea superba and Gentiana straminea is not reduced after long-term enhancement of UV-B radiation. Environ Exp Bot, 2004, 51: 75-83

40 He J S, Chen W L, Wang X L. Morphological and anatomical features of Quercus section and its adaption to the ecological environment. Acta Phytoecol Sin, 1994, 18: 219-227

41 Yan L, Li H, Liu Y. The anatomical ecology studies on the leaf of 13 species in Caragana genus. J Arid Land Resour Environ, 2002, 16: 100-106

42 da Costa R C, de Araujo F S, Lima-Verde L W. Flora and life-form spectrum in an area of deciduous thorn woodland (Caatinga) in northeastern, Brazil. J Arid Environ, 2007, 68: 237-247

43 Li Y L, Mao W, Zhao X Y, et al. Leaf nitrogen and phosphorus stoichiometry in typical desert and desertified regions, North China. Environ Sci, 2010, 31: 1716-1725

44 Ding T, Du F, Wang J, et al. Analysis on life form characteristics of the mid-montane humid evergreen broad-leaved forest in Lancangjiang Nature Reserve. J Southwest Forestry College, 2006, 26: $19-23$

45 Lin Y M, Wu C Z, Hong W, et al. Analysis on characteristics of plant life-form and leaf in rare and endangered plant Tsuga longibracteata community. J Plant Resour Environ, 2004, 13: 35-38

46 Huang J J, Wang X H. Leaf nutrient and structural characteristics of 32 evergreen broad-leaved species. J Eastchina Normal Univ (Nat Sci), 2003, 14: 92-97

47 Liu M Z, Jiang G M, Li Y K, et al. Hydrological characteristics of different species in three habitats of Hunshandak Sandland. Acta Ecol Sin, 2004, 24: 1465-1471

48 Wright I J, Reich P B, Westoby M, et al. The worldwide leaf economics spectrum. Nature, 2004, 428: 821-827

Open Access This article is distributed under the terms of the Creative Commons Attribution License which permits any use, distribution, and reproduction in any medium, provided the original author(s) and source are credited. 